Fixed Point Theory, 21(2020), No. 1, 109-124

DOI: $10.24193 /$ fpt-ro.2020.1.08

http://www.math.ubbcluj.ro/ nodeacj/sfptcj.html

\title{
A NEW ITERATIVE ALGORITHM FOR A GENERALIZED MIXED EQUILIBRIUM PROBLEM AND A COUNTABLE FAMILY OF NONEXPANSIVE-TYPE MAPS WITH APPLICATIONS
}

\author{
C.E. CHIDUME*, M.O. NNAKWE** AND E.E. OTUBO*** \\ *Institute of Mathematics, African University of Science and Technology, Abuja, Nigeria \\ E-mail: cchidume@aust.edu.ng \\ ${ }^{* *}$ Institute of Mathematics, African University of Science and Technology, Abuja, Nigeria \\ E-mail: mondaynnakwe@gmail.com \\ *** Institute of Mathematics, African University of Science and Technology, Abuja, Nigeria \\ and \\ Ebonyi State University, Abakaliki, Nigeria \\ E-mail:mrzzaka@yahoo.com
}

\begin{abstract}
Let $C$ be a nonempty closed and convex subset of a uniformly smooth and uniformly convex real Banach space with dual space $E^{*}$. In this paper, a new iterative algorithm of Krasnoselskiitype is constructed and used to approximate a common element of a generalized mixed equilibrium problem and a common fixed point of a countable family of generalized- $J$-nonexpansive maps. Applications of our theorem, in the case of real Hilbert spaces, complement and extend the results of Peng and Yao, (Taiwanese Journal of Mathematics Vol. 12, No. 6, pp. 1401-1432, September 2008); Nakajo and Takahashi, (J. Math. Anal. Appl. 273 (2003) 372-379); Martinez-Yanes and Xu, (Nonlinear Anal., 64 (2006), 2400-2411); Qin and Su, (J. Syst. Sci. and Complexity 21(2008) 474-482)

Key Words and Phrases: Generalized mixed equilibrium problem, nonexpansive-type maps,
\end{abstract} monotone maps, strong convergence.

2010 Mathematics Subject Classification: 47H09, 47H10, 47J25 47J05, 47J20.

\section{REFERENCES}

[1] Y. Alber, Metric and generalized projection operators in Banach spaces: properties and applications, in: Theory and Applications of Nonlininear Operators of Accretive and Monotone Type (A. G. Kartsatos, Ed.), Marcel Dekker, New York (1996), 15-50.

[2] Y. Alber, S. Guerre-Delabriere, On the projection methods for fixed point problemss, Analysis (Munich), 21(2001), no. 1, 17-39.

[3] Y. Alber, I. Ryazantseva, Nonlinear Ill Posed Problems of Monotone Type, Springer, London, UK, 2006.

[4] K. Aoyama, Y. Kimura, Strong convergence theorems for strongly nonexpansive sequences, Appl. Math. Comput., 217(2011), 7537-7545.

Research supported from ACBF Research Grant Funds to AUST. 
[5] F.E. Browder, Existence and approximation of solutions of nonlinear variational inequalities, Proc. Natl. Acad. Sci. USA, 56(1966), no. 4, 1080-1086.

[6] C.E. Chidume, Geometric Properties of Banach Spaces and Nonlinear Iterations, vol. 1965, Lecture Notes in Mathematics, Springer, London, 2009.

[7] C.E. Chidume, K.O. Idu, Approximation of zeros of bounded maximal monotone maps, solutions of Hammerstein integral equations and convex minimization problems, Fixed Point Theory Appl., (2016), 97:2016, DOI: 10.1186/s13663-016-0582-8.

[8] C.E. Chidume, E.U. Ofoedu, Approximation of common fixed points for finite families of total asymptotically nonexpansive mappings, J. Math. Anal. Appl., 333(2007), 128-141.

[9] C.E. Chidume, E.E. Otubo, C.G. Ezea, M.O. Uba, A new monotone hybrid algorithm for a convex feasibility problems for an finite family of nonexpansive-type maps with applications, Advances in Fixed Point Theory Appl., 7(2017), no. 3, 413-431.

[10] I. Cioranescu, Geometry of Banach Spaces, Duality Mappings and Nonlinear Problems, vol. 62, Kluwer Academic Publisher, 1990.

[11] J.N. Ezeora, Convergence theorem for generalized mixed equilibrium problems and common fixed point problems for a family of multivalued mappings, International J. Anal. Appl., 10(2016), no. $1,48-57$.

[12] T. Ibaraki, W. Takahashi, A new projection and convergence theorems for the projections in Banach spaces, J. Approx. Theory, 149(2007), 1-14.

[13] S. Kamimura, W. Takahashi, Strong convergence of a proximal-type algorithm in a Banach space, SIAM J. Optim., 13(2002), no. 3, 938-945.

[14] C. Klin-eam, S. Suantai, W. Takahashi, Strong convergence theorems by monotone hybrid method for a family of generalized nonexpansive mappings in Banach spaces, Taiwanese J. Math., 16(2012), no. 6, 1971-1989.

[15] F. Kohsaka, W. Takahashi, Generalized nonexpansive retractions and a proximal-type algorithm in Banach spaces, J. Nonlinear Convex Anal., 8(2007), no. 2, 197-209.

[16] B. Liu, Fixed point of strong duality pseudocontractive mappings and applications, Abstract Applied Anal., Vol. 2012, Art. ID 623625, 7 pages, DOI: 10.1155/2012/623625.

[17] C. Martinez-Yanes, H.K. Xu, Strong convergence of the CQ method for fixed point iteration processes, Nonlinear Anal., 64(2006), 2400-2411.

[18] S. Matsushita, W. Takahashi, Weak and strong convergence theorems for relatively nonexpansive mappings in a Banach space, Fixed Point Theory Appl., 2004(2004), 37-47.

[19] S. Matsushita, W. Takahashi, A strong convergence theorem for relatively nonexpansive mappings in a Banach space, J. Approx. Theory, 134(2005), 257-266.

[20] A. Moudafi, M. Thera, Proximal and dynamical approaches to equilibrium problems, in: Illposed Variational Problems and Regularization Techniques, Lect. Notes in Economics and Mathematics Systems, vol. 477, Springer, 1999, 187-201.

[21] K. Nakajo, W. Takahashi, Strong convergence theorems for nonexpansive mappings and nonexpansive semigroups, J. Math. Anal. Appl., 279(2003), 372-379.

[22] K. Nakajo, K. Shimoji, W. Takahashi, Strong convergence theorems to common fixed points of families of nonexpansive mappings in Banach spaces, J. Nonlinear Convex Anal., (2007), 11-34.

[23] N. Onjai-uea, P. Kumam, Algorithms of common solutions to generalized mixed equilibrium problem and a system of quasi variational inclusions for two difference nonlinear operators in Banach spaces, Fixed Point Theory Appl., Vol. 2011, Art. ID 601910, 23 pages, doi:10.1155/2011/601910.

[24] J. Peng, J. Yao, A new hybrid-extragradient method for generalized mixed equilibrium problems, fixed point problems and variational inequality problems, Taiwanese J. Math., 12(2008), no. 6, 1401-1432.

[25] X.L. Qin, Y.J. Cho, S.M. Kang, H.Y. Zhou, Convergence of a modified Halpern-type iterative algorithm for quasi- $\phi$-nonexpansive mappings, Appl. Math. Lett., 22(2009), 1051-1055.

[26] X. Qin, Y. Su, Strong convergence theorems for relatively nonexpansive mappings in a Banach space, Nonlinear Anal., 67(2007), 1958-1965.

[27] X. Qin, Y. Su, Strong convergence of monotone hybrid method for fixed point iteration process, J. Syst. Sci. Complexity, 21(2008), 474-482. 
[28] C. Suanoom, C. Klin-earn, W. Khuangsatung, Convergence theorems for a bivariate nonexpansive opreator, Adv. Fixed Point Theory, 8(2018), no. 3, 274-286.

[29] P. Sunthrayuth, P. Kumam, A system of generalized mixed equilibrium problems, maximal monotone operators, and fixed point problems with application to optimization problems, Abstract Applied Anal., Vol. 2012, Art. ID 316276, 39 pages, DOI: 10.1155/2012/316276.

[30] W. Takahashi, K. Zembayashi, Strong convergence theorem by a new hybrid method for equilibrium problems and relatively nonexpansive mappings, Fixed Point Theory and Applications, Vol. 2008, Art. ID 528476, 11 pages, DOI: 10.1155/2008/528476.

[31] H.K. Xu, Inequalities in Banach spaces with applications, Nonlinear Anal. TMA, 16(1991), no. $12,1127-1138$

[32] H. Zegeye, Strong convergence theorems for maximal monotone mappings in Banach spaces, J. Math. Anal. Appl., 343(2008), 663-671.

Received: September 21, 2017; Accepted: June 4, 2019. 
